\title{
Cesarean Section Rate among COVID-19 Mothers and Its Classification through Robson's Criteria
}

\author{
Ruchi Bisht ${ }^{1}$, Vishakha P Kandalgaonkar ${ }^{2}$, Kunaal K Shinde ${ }^{3}$
}

\begin{abstract}
Background: The COVID-19 epidemic that erupted in November 2019 has brought medical science to the fore in news and public perceptions. As the pandemic enters the next phase with new diversity, there are various concerns regarding pregnant women, its transmission to the unborn child, and the safe and secure method of childbirth. Both the method of vaginal delivery and the delivery phase are equally appropriate. The mode of birth a woman should go through must be personal and based entirely on the severity of the disease and obstetric indications.

Methods: This was a 1-year retrospective study from April 2020 to April 2021 in the Department of Obstetrics and Gynecology of the Postgraduate Institute Yashwantrao Chavan Memorial Hospital, Pimpri, Pune. All pregnant women admitted irrespective of their gestational age or whether they were in labor or not were universally screened for COVID-19. All the delivered women were segregated based on the mode of delivery, vaginal or cesarean, and the information was then classified according to Robson's policy.

Results: The rate of cesarean section in COVID-19 patients during this 1-year period was $31.59 \%$. Also, it was noted that the maternal mortality was more in the cases of cesarean section (1.4\%) compared to vaginal delivery ( $0.00 \%)$. The percentage of neonates affected by COVID-19 in cesarean delivery $(0.46 \%)$ was more than in vaginal delivery $(0.22 \%)$.

Conclusion: We conclude that there is insufficient evidence to support that the outcome of lower-segment cesarean section (LSCS) was better than vaginal delivery to prevent direct transmission from a COVID-19 pregnant mother to the neonate. The mode of delivery should be individualized and based on the severity of the disease and obstetrical indications. Therefore, in mild cases, it is advisable to continue with vaginal delivery and LSCS should be reserved for women with severe respiratory problems, where termination of pregnancy will allow for better ventilation of the newborn.
\end{abstract}

Keywords: COVID-19, Cesarean section, Robson's criteria.

Journal of South Asian Federation of Obstetrics and Gynaecology (2021): 10.5005/jp-journals-10006-1921

\section{INTRODUCTION}

In December 2019, there was an outbreak of a severe paralysis of coronavirus 2 (SARS-CoV-2), isolated among pneumonia patients in Wuhan, Hubei, China. ${ }^{1}$ The disease due to the virus was named coronavirus-2019 (COVID-19), which can cause negative or positive symptoms and in severe attacks, life-threatening respiratory illnesses. ${ }^{2-5}$ Since then, there has been an increase in the number of pregnant women affected by COVID-19. Women giving birth and newborns are the most affected people, and this continues to require safe family-based care during the epidemic.

Pregnancy is manifested by the immune system, and these women are affected by respiratory infections, even COVID-19., ${ }^{6,7}$ Enlarged uterus causes a decrease in total lung volume, which may be an additional factor in the rapid clinical decline in COVID-19 during pregnancy, which also increases the risk of side effects of pregnancy.

The World Health Organization (WHO), ${ }^{8}$ the Royal College of Obstetricians and Gynaecologists, and the Royal College of Midwives evaluate each delivery method, but all options must be given to gravid women, empowering every woman to make the right decision for them.

The presence of COVID-19 infection should not affect the mode of birth unless emergency intervention is necessary when considering a woman's respiratory status. ${ }^{8,9}$ An informed individual choice should be made with regard to reducing the duration of the second stage of labor in a woman with symptoms of fatigue or hypoxia. ${ }^{9}$
${ }^{1-3}$ Department of Obstetrics and Gynecology, Postgraduate Institute Yashwantrao Chavan Memorial Hospital, Pune, Maharashtra, India

Corresponding Author: Kunaal K Shinde, Department of Obstetrics and Gynecology, Postgraduate Institute Yashwantrao Chavan Memorial Hospital, Pune, Maharashtra, India, Phone: +91 7507351235, e-mail: dr.kunaal.shinde@gmail.com

How to cite this article: Bisht R, Kandalgaonkar VP, Shinde KK. Cesarean Section Rate among COVID-19 Mothers and Its Classification through Robson's Criteria. J South Asian Feder Obst Gynae 2021;13(5):355-359. Source of support: Nil

Conflict of interest: None

A cesarean section as a mode for termination of pregnancy is not recommended in COVID-19; however, in most cases, it was the preferred delivery method with an indication of fetal distress. ${ }^{10,11}$ There was no evidence of a COVID-19 infection in samples collected from amniotic fluid, umbilical cord, and neonatal throat swab or breast milk. ${ }^{9}$ No vertical transmission was reported in newborns.

As recommended by $\mathrm{WHO}$ and US guidelines for healthy action 2000 , the cesarean section rate should not exceed $15 \% .{ }^{12}$ However, there was an increasing trend of cesarean section, especially in COVID-19 patients. As a matter of concern regarding global public health, the increasing rate of cesarean section is associated with maternal morbidity. ${ }^{13-15}$

(o) The Author(s). 2021 Open Access This article is distributed under the terms of the Creative Commons Attribution 4.0 International License (https://creativecommons. org/licenses/by-nc/4.0/), which permits unrestricted use, distribution, and non-commercial reproduction in any medium, provided you give appropriate credit to the original author(s) and the source, provide a link to the Creative Commons license, and indicate if changes were made. The Creative Commons Public Domain Dedication waiver (http://creativecommons.org/publicdomain/zero/1.0/) applies to the data made available in this article, unless otherwise stated. 
The maternity category is therefore categorized by Robson's criteria within the healthcare facilities as proposed by M.S. Robson in 2001. A group of 10 named Robson's classification of cesarean section have been approved by WHO in 2014 and the International Federation of Gynecology and Obstetrics in 2016. ${ }^{12,16}$ According to the WHO, Robson's classification will aid in the optimization of cesarean section rate and assessment of strategies aimed at reducing lower-segment cesarean section (LSCS), thus improving clinical practice and quality care in various healthcare facilities. Therefore, we have made an effort to classify the cesarean section from the positive patients of COVID-19 based on this program to address the cause of the increasing LSCS in our scenario.

The objectives of the study were:

- To calculate the rate of cesarean section in COVID-19 patients.

- To classify the cesarean section according to their causes.

\section{Methods}

This was a retrospective study over a period of 1 year from April 2020 to April 2021 in the Department of Obstetrics and Gynecology, PGI YCMH, Pimpri, Pune. All data were retrieved and entered in a preformed, structured pro forma. All admitted gravid patients were subjected to universal screening for COVID-19 irrespective of their gestational age or whether they were in labor or not.

\section{Inclusion Criteria}

COVID-19-positive patients who underwent cesarean section during the above-mentioned time frame (April 2020-April 2021) were documented and categorized according to Robson's 10-group classification system as given in Table 1. The parameters considered according to the classification system were:

- Parity (with/without previous CS)

- Gestational age (>37/<36 weeks)

- Fetal presentation (cephalic/breech/abnormal lie)

- Number of fetuses (singleton/multiple)

- Onset of labor (spontaneous/induced/prelabor CS) (Table 1).

\section{Exclusion Criteria}

- Term/preterm normal or instrumental vaginally delivered patients.
- Term/preterm non-COVID-19 patients delivered by cesarean section.

Data collected were analyzed using simple statistical measures like percentage and proportion. A descriptive statistical analysis was done.

\section{Results}

The total number of COVID-19-positive deliveries over this period in the hospital was 652; of which the number of cesarean sections was 206 which denotes that the percentage of cesarean section was $31.59 \%$, which is also called the rate of cesarean section in layman terms.

The data were analyzed as shown in Table 2.

Previous cesarean sections which are included in group 5 made most of the contribution with 82 cases, while 4 cases were subjected to trial of labor after cesarean after the assessment of success rate using Flamm score and counseling them about the risks and benefits of VBAC. It was unknown in the earlier stage of

Table 1: Robson's classification of cesarean section ${ }^{17,18}$

\begin{tabular}{|c|c|}
\hline Group & Description \\
\hline 1 & $\begin{array}{l}\text { Nulliparous, single, cephalic, } \geq 37 \text { weeks, spontaneous } \\
\text { labor }\end{array}$ \\
\hline $2 \mathrm{~A}$ & Nulliparous, single, cephalic, $\geq 37$ weeks, induced labor \\
\hline $2 \mathrm{~B}$ & $\begin{array}{l}\text { Nulliparous, single, cephalic, } \geq 37 \text { weeks, cesarean before } \\
\text { labor }\end{array}$ \\
\hline 3 & $\begin{array}{l}\text { Multiparous (excluding previous cesareans), single, } \\
\text { cephalic, } \geq 37 \text { weeks, spontaneous labor }\end{array}$ \\
\hline $4 \mathrm{~A}$ & $\begin{array}{l}\text { Multiparous (excluding previous cesareans), single, } \\
\text { cephalic, } \geq 37 \text { weeks, induced labor }\end{array}$ \\
\hline 4B & $\begin{array}{l}\text { Multiparous (excluding previous cesareans), single, } \\
\text { cephalic, } \geq 37 \text { weeks, cesarean before labor }\end{array}$ \\
\hline 5 & Previous cesareans, single, cephalic, $\geq 37$ weeks \\
\hline 6 & All nulliparous breeches \\
\hline 7 & All multiparous breeches (including previous cesareans) \\
\hline 8 & All multiple pregnancies (including previous cesareans) \\
\hline 9 & All abnormal lies (including previous cesareans) \\
\hline 10 & All single, cephalic, $<36$ weeks (including previous cesareans) \\
\hline
\end{tabular}

Table 2: Classification of cesarean section according to Robson's classification

\begin{tabular}{|c|c|c|c|c|c|c|}
\hline $\begin{array}{l}\text { Robson's } \\
\text { criteria }\end{array}$ & $\begin{array}{l}\text { Total no. of vaginal } \\
\text { deliveries in each } \\
\text { group }\end{array}$ & $\begin{array}{l}\text { Total no. of cesarean } \\
\text { sections in each group }\end{array}$ & $\begin{array}{l}\text { Total no. of deliveries } \\
\text { in each group }\end{array}$ & $\begin{array}{l}\text { Relative size } \\
\text { of the group } \\
\text { (\%) }\end{array}$ & $\begin{array}{l}\text { Cesarean section } \\
\text { rate percentage }\end{array}$ & $\begin{array}{c}\text { Contribution made by each } \\
\text { group to total cesarean } \\
\text { section rate (\%) }\end{array}$ \\
\hline 1 & 102 & 28 & 130 & 19.9 & 21.5 & 4.2 \\
\hline $2 \mathrm{~A}$ & 73 & 7 & 80 & 12.2 & 8.7 & 1.07 \\
\hline $2 B$ & 0 & 33 & 33 & 5.05 & 100 & 5.06 \\
\hline 3 & 98 & 6 & 104 & 15.9 & 5.7 & 0.92 \\
\hline $4 \mathrm{~A}$ & 64 & 2 & 66 & 10.1 & 3.03 & 0.3 \\
\hline $4 B$ & 0 & 4 & 4 & 0.6 & 100 & 0.61 \\
\hline 5 & 4 & 82 & 86 & 13.1 & 95.3 & 12.5 \\
\hline 6 & 2 & 6 & 8 & 1.2 & 75 & 0.92 \\
\hline 7 & 4 & 5 & 9 & 1.3 & 55.5 & 0.76 \\
\hline 8 & 6 & 7 & 13 & 1.9 & 53.8 & 1.07 \\
\hline 9 & 0 & 6 & 6 & 0.9 & 100 & 0.92 \\
\hline 10 & 93 & 20 & 113 & 17.3 & 17.6 & 3.06 \\
\hline
\end{tabular}


pandemic regarding the vertical transmission of the virus. Group 2B (nulliparous, singleton, cephalic, $\geq 37$ weeks, cesarean before labor) had the second-largest share to the CS rate with 33 cases, with the major indication being cephalopelvic disproportion and prelabor rupture of membranes. These were followed by group 1 (nulliparous, singleton, cephalic, $\geq 37$ weeks, spontaneous labor) placed third with 28 cases.

The cesarean section rate in group 1 (nulliparous, singleton, cephalic, $\geq 37$ weeks, spontaneous labor) (4.2\%) and 3 (multiparous without previous cesarean section, singleton, cephalic, $\geq 37$ weeks, spontaneous labor) (0.92\%) was less as they came in spontaneous labor as compared to group 2 (nulliparous, singleton, cephalic, $\geq 37$ weeks, induced labor, or cesarean section before labor) (6.13\%) (Fig. 1).

For both nulliparous and multiparous breeches, the cesarean section rate was more compared to vaginal delivery. Most of the patients were in home isolation as per the local government guidelines. The patients had regular follow-ups antenatally. But, due to imposed strict nationwide lockdown, many patients found it difficult to arrange travel to the hospital timely, so by the time they reached our institution, they were already breech on the perineum.

The cesarean section rate percentage for group 6 (all nulliparous breeches) and group 7 (all multiparous breeches including previous cesareans) was 75 and $55.5 \%$, respectively. The contribution by the two groups was 0.92 and $0.76 \%$, respectively.

In the case of group 9 (all abnormal lies [including previous cesareans]), the cesarean section rate percentage was $100 \%$ as vaginal delivery is not indicated. The total contribution made was $0.92 \%$. The indications included transverse lie in four cases and compound presentation in two cases.

Lastly, group 10 (all singleton, cephalic, $<36$ weeks [including previous cesareans]) contributed 3.06\%.

Of all the pregnant women analyzed, the median age was 22 years (range 18-36). Of those pregnant women who tested positive for SARS-CoV-2, 539 of 652 (82.7\%) had term delivery and 113 of 652 (17.3\%) had preterm delivery, and there were no neonatal deaths.

Two hundred thirteen (32.03\%) neonates were delivered through cesarean section and 452 (67.96\%) were delivered through vaginal delivery. The probable congenital SARS-CoV-2 infections

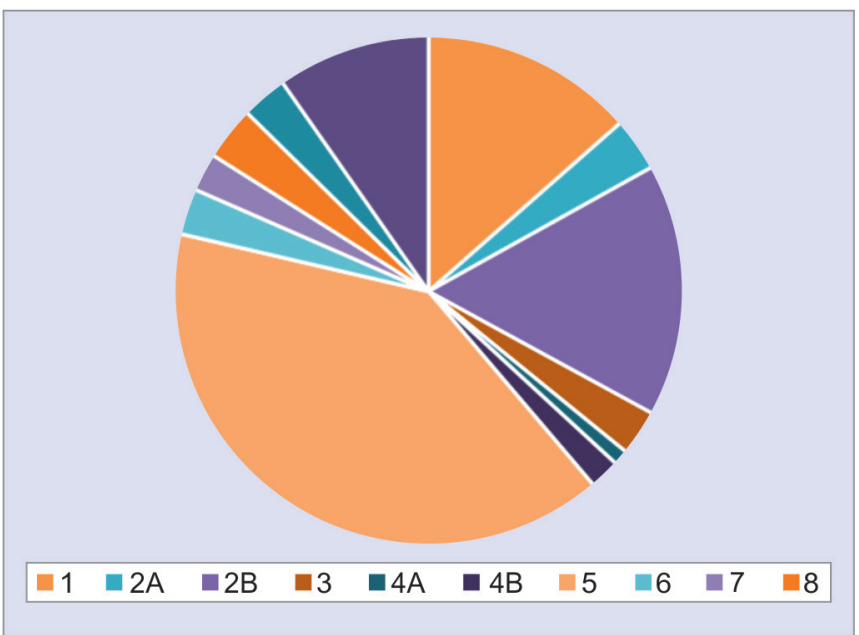

Fig. 1: Cesarean section rate according to Robson's classification in COVID-19 pregnant mothers were reported in $2 / 665(0.3 \%)$ neonates. Of babies born vaginally, $1 / 452(0.22 \%)$ were tested positive compared with $1 / 213(0.46 \%)$ born by cesarean. Of babies born vaginally and by cesarean section, zero neonatal deaths were reported.

Of women who delivered vaginally, 0/452 (0.00\%) maternal deaths were reported as compared to $3 / 213$ (1.40\%) delivered by cesarean section. Five women died before delivery and one died post-exploratory laparotomy done for an ectopic pregnancy.

\section{Discussion}

COVID-19 has been shown to be a deadly disease. Pregnancy is characterized by the immune system and these women are more susceptible to respiratory infections, even COVID-19, compared to women who are not gravitational powers. The COVID-19 virus has been found to have adverse effects on its mother. When it comes to the management of pregnancy for pregnant women with COVID-19, it is a critical decision-making process that is important in obtaining a good maternal prognosis and preventing infection in newborns. In addition, further research is needed to determine the effectiveness of the hypothesis of direct transmission of COVID-19 from mother to child.

In this rapidly changing situation, the health of pregnant women needs to be carefully monitored. The WHO reported that there was no significant difference in the risk of developing clinical symptoms among gravid women and nongravid women of reproductive age..$^{17}$

There are about 140 million births each year, and pregnant women could be at risk of serious side effects of COVID-19 infection. The goal of COVID-19 obstetric management includes early detection, isolation and testing, deep prevention methods, general fetal monitoring and intrauterine contraception, a different case in the delivery system, depending on the severity of the symptoms, and appropriate measures to prevent postpartum infection.

All healthy COVID-19 patients underwent standard blood tests, such as D-dimer, CRP, ESR, and serum ferritin levels. Chest $X$-ray-posteroanterior (CXR-PA) screening of the abdomen is recommended for female patients with elevated $D$-dimer symptoms (normal values in the first trimester of pregnancy $167-721 \mathrm{ng} / \mathrm{mL}$, second trimester of pregnancy $298-1653 \mathrm{ng} / \mathrm{mL}$, and third trimester of pregnancy $483-2256 \mathrm{ng} / \mathrm{mL}$ ), and low-molecular-weight heparin is initiated. Patients with symptoms with confused lab counts and CXR are introduced to injectable steroids. Generally, termination of pregnancy is postponed until the 10th day of the swab or until the patient has symptoms when the patient is absent from activities to reduce the risk of transmitting the infection to the child and healthcare providers.

Emergency delivery is done regardless of the swab day when the patient is in labor. Delivery mode is determined by disease severity and obstetric indications.

In the present study, estimates in maternity delivery were made following Robson's criteria in a concerted effort to determine which clinically appropriate groups contributed most to the delivery of cesarean to COVID-19 soft tissue patients.

As we have seen in the current study, the birth rate in good patients with COVID-19 (31.59\%) is much higher than what WHO assumed (15\%).

The rate of women having previous cesarean stages has increased as well as the rate of childbearing in these women as we see in the present study. 
The second-largest proportion of COVID-positive section is the nulliparous women prior to labor. The most common indication was the positive condition of COVID-19 alone during the first months of the epidemic, although there was no evidence of vertical transmission. The increased cesarean sections in this data may reflect the real intentions of the specialists who are trying to serve their patients in the best possible way considering the ever-changing guidelines in safe mode for the delivery of mothers, infants, and healthcare providers. While we keep current recommendations from reputable organizations as new information is published while continuing to provide individual support to pregnant women with the most appropriate mode of delivery, it will reduce the number of unnecessary, unplanned LSCS and can help reduce the psychological impact of delivery.

The overall birth rate in the included studies was $31.59 \%$ (206/652), which was about the same as the birth rates for women who gave birth in the United States (31.9\%) and China $(36.7 \%)^{18,19}$

A recent systematic review from Bologna, Italy, by Della Gatta et al. found that of the 51 women diagnosed with COVID-19, 46 $(90.2 \%)$ women underwent surgery. ${ }^{20}$ A series of recent cases in New York City found that of the 18 women affected by COVID-19 who delivered between March 13 and March 27, 2020, 8 (44.4\%) had a cesarean section. ${ }^{21}$

In addition, cesarean sections were associated with a much higher risk of maternal deaths than vaginal delivery. In addition, cesarean delivery is associated with increased morbidity during early childbirth due to an increased risk of blood loss and thromboembolic disease. Currently, there is insufficient evidence to support that cesarean section improves outcomes among patients with COVID-19 and prevents mother-to-child transmission. Therefore, the presence of COVID-19 infection should not be an indication of surgical birth.

\section{Conclusion}

The birth of the COVID-19 epidemic can be treated as tokophobia. Women, which are not always the case of "obedient" consumers, may choose the surgical category with uncertainty about their physical strength in the delivery of genitals. There is a significant influence on the media and believers in technology, opening the way for a new understanding of safe births during the epidemic with partial surgery. Therefore, it is important on the part of doctors and health professionals to guide women properly. The birth mode should be categorized by each pregnant woman and based on female preferences and maternity indications.

There were no significant differences in newborn COVID-19 infection, neonatal mortality, or maternal mortality compared between female vaginal delivery and surgery. According to the available literature, there is no evidence to support the idea that birth can be better than the delivery of a woman's vagina in preventing mother-to-child transmission. The delivery mode should be individualized and based on female preferences and delivery indicators.

In conclusion, vaginal delivery should be considered appropriate in mild cases and the cesarean section should be kept reserved in women with severe respiratory symptoms, where termination of pregnancy will allow for a better outcome of the baby.

\section{References}

1. Tian H, Liu Y, Li Y, et al. An investigation of transmission control measures during the first 50 days of the COVID-19 epidemic in China. Science 2020;368(6491):638-642. DOI: 10.1126/science.abb6105.

2. Chen G, Wu D, Guo W, et al. Clinical and immunological features of severe and moderate coronavirus disease 2019. J Clin Invest 2020;130(5):2620-2629. DOI: 10.1172/JCI137244.

3. Chan JF, Yuan S, Kok KH, et al. A familial cluster of pneumonia associated with the 2019 novel coronavirus indicating person-toperson transmission: a study of a family cluster. Lancet 2020;395(10223): 514-523. DOI: 10.1016/S0140-6736(20)30154-9.

4. Hoehl S, Rabenau H, Berger A, et al. Evidence of SARS-CoV-2 infection in returning travellers from Wuhan, China. N Engl J Med 2020;382(13):1278-1280. DOI: 10.1056/NEJMc2001899.

5. Jones DS. History in a crisis - lessons for Covid-19. N Engl J Med 2020;382(18):1681-1683. DOI: 10.1056/NEJMp2004361.

6. Liu H, Wang LL, Zhao SJ, et al. Why are pregnant women susceptible to COVID-19? An immunological viewpoint. J Reprod Immunol 2020;139:103122. DOI: 10.1016/j.jri.2020.103122.

7. Liu Y, Chen $\mathrm{H}$, Tang K, et al. Clinical manifestations and outcome of SARS-CoV-2 infection during pregnancy. J Infect 2020;48:436-443. DOI: 10.1016/j.jinf.2020.02.028.

8. World Health Organization. Clinical management of severe acute respiratory infection (SARI) when COVID-19 disease is suspected: Interim guidance. Available from: https://apps.who.int/iris/bitstream/ handle/10665/331446/WHO-2019-nCoVclinical-2020.4-eng. pdf?sequence=1\&isAllowed=y. 2020 [Accessed May 5, 2020].

9. The Royal College of Obstetricians and Gynaecologists, Royal College of Midwives. Coronavirus (COVID-19) infection in pregnancy: Information for healthcare professionals. Available from: https:// www.rcog.org.uk/globalassets/documents/guidelines/202006-04-coronavirus-covid-19-infection-in-pregnancy.pdf. 2020 [Accessed May 5, 2020].

10. Chen $\mathrm{H}$, Guo J, Wang C, et al. Clinical characteristics and intrauterine vertical transmission potential of COVID-19 infection in nine pregnant women: a retrospective review of medical records. Lancet 2020;395(10226):809-815. DOI: 10.1016/s0140-6736(20)30360-3.

11. Liu H, Liu F, Li J, et al. Clinical and CT imaging features of the COVID-19 pneumonia: focus on pregnant women and children. J Infect 2020;80(5):e7-e13. DOI: 10.1016/j.jinf.2020.03.007.

12. WHO statement on cesarean section rates. WHO/RHR/15.02. Available from: http://www.who.int/reproductivehealth/ publications/maternal_perinatal_health/cs-statement/en /.

13. Lumbiganon P, Laopaiboon M, Gulmezoglu AM, et al. Method of delivery and pregnancy outcomes in Asia: the WHO global survey on maternal and perinatal health 2007-08. Lancet 2010;375(9713): 490-499. DOI: 10.1016/S0140-6736(09)61870-5.

14. Marshall NE, Fu R, Guise JM. Impact of multiple cesarean deliveries on maternal morbidity: a systematic review. Am J Obstet Gynecol 2011;205(3):262.e1-262.e8. DOI: 10.1016/j.ajog.2011.06.035.

15. Souza JP, Gülmezoglu AM, Lumbiganon P, et al. Caesarean section without medical indications is associated with an increased risk of adverse short-term maternal outcomes: the 2004-2008 WHO Global Survey on Maternal Perinatal Health. BMC Med 2010;8(1):71. DOI: 10.1186/1741-7015-8-71.

16. FIGO Working Group on Challenges in Care of Mothers and Infants during Labour and Delivery Best practise advice on the 10-group classification system for caesarean deliveries. Int J Gynecol Obstet 2016;135(2);232-233. DOI: 10.1016/j.ijgo.2016.08.001.

17. Robson M, Murphy M, Byrne F. Quality assurance: the 10-group classification system (Robson classification), induction of labour and Caesarean delivery. Int J Gynaecol Obstet 2015;131(S1):S23-S27. DOI: 10.1016/j.ijgo.2015.04.026

18. Martin JA, Hamilton BE, Osterman MJK, et al. Births: final data for 2018. Natl Vital Stat Rep 2019;68(13):1-47. Available from: https://www.cdc. gov/nchs/data/nvsr/nvsr68/nvsr68_13-508.pdf. PMID: 33814033. 
19. The National Health Commission of China. Report on the development of maternal and child health in China. 2019.

20. Della Gatta AN, Rizzo R, Pilu G, et al. COVID19 during pregnancy: a systematic review of reported cases. Am J Obstet Gynecol. 2020;223(1):36-41. DOI: 10.1016/j.ajog.2020.04.013.
21. Breslin N, Baptiste C, Gyamfi-Bannerman C, et al. Coronavirus disease 2019 infection among asymptomatic and symptomatic pregnant women: two weeks of confirmed presentations to an affiliated pair of New York City hospitals. Am J Obstet Gynecol MFM 2020;2(2):100118. DOI: 10.1016/j.ajogmf.2020.100118. 